\title{
COMPARATIVE STUDIES FOR DETECTION OF BRUCELLA MICRO-ORGANISM IN ABORTED BOVINE FOETI USING CONVENTIONAL, IMMUNOHISTOCHEMICAL AND MOLECULAR METHODS
}

\author{
SOLIMAN S. HAZEM ${ }^{1}$ and NIBAL A. HASSAN ${ }^{2}$ \\ ${ }^{1}$ Department of Brucella, Animal Health Research Institute, Giza, Egypt. \\ ${ }^{2}$ Department of Pathology, Animal Reproduction Research Institute-Haram-Giza-Egypt.
}

Received: 27 February 2017; Accepted: 27 March 2017

\begin{abstract}
The present study was carried out on a total number of 78 bovine (cows48- Buffaloes 30) The obtained sera were investigated for detection of brucella-antibody titer using serological tests Rose Bengal plate Test (RBPT), Tube agglutination test (TAT), indirect ELISA (iELISA) and Complement Fixation Test (CFT). Abomasal content were collected from 78 aborted fetuses for bacteriological and Polymerase Chain Reaction (PCR) assays. The results of serological analysis revealed that the positive reactors were 60 (76.92\%), 55 (70.51\%), 58 (74.36 $\%)$ and $57(73.08 \%)$ using RBPT, TAT, iELISA and CFT, respectively. RBPT and iELISA tests showed the highest seropositivity. Meanwhile, the lowest ones were obtained by TAT and CFT tests. Brucellaem elitensis biovar3 was isolated from 31 out of 48cows (abomasal content) aborted fetuses and 21 out of 30buffaloes (abomasal content) aborted fetuses. PCR assay for detection of Brucella in aborted fetuses were 33 out of 48 in cow and 22 out of 30 in buffaloes. Pathological examination in organs of aborted fetuses infected by Brucella melitensis showed significantly pathological lesions in lungs, liver, spleen and placenta. Immunohistochemistry revealed the presence of positive immunostaining brucella antigen in formalin-fixed, paraffin imbedded tissue sections of lung, liver, spleen, and placenta by using avidin-biotin complex peroxidase technique. Electron microscopical finding of lung, liver and spleen showed that the cytoplasm of neutrophil and macrophages containing dark bodies of cocobacilli. TEM of placenta revealed that the Trophoblasts filled with degenerated organisms.
\end{abstract}

Key words: Brucella, serology, molecular, pathology, immunohistochemical.

\section{INTRODUCTION}

Brucellosis is a prevalent zoonotic disease affecting both humans and animals caused by bacteria of the genus Brucella (WHO/OIE/FAO/CDS 2006). It is found to be one of the most common public health problems all over the world (Kardjadj et al., 2016). Brucellae are facultative gram negative intracellular bacteria of genus Brucella which are survivors in both extracellular and intracellular environments. The main domestic animals that are affected are cattle, sheep, goats and pigs, (Nicoletti and Tanya, 1993). It is known to be a worldwide problem and one of the most important among zoonoses in the Mediterranean region, India, and Central and South America (Ashford et al., 2004). Outbreaks of bovine brucellosis are associated with abortion during the last trimester of gestation, and produces weak newborn calves, and infertility in cows and bulls (Megid et al., 2010).

Corresponding author: Dr. SOLIMAN S. HAZEM

E-mail address: hazemsoliman144@gmail.com

Present address: Department of Brucella, Animal Health Research Institute, Giza, Egypt.
Precise diagnosis of livestock and humans brucellosis is considered the keystone for its correct abolition and manages. In general, diagnosis of brucellosis is somewhat difficult as the disease may have an incubation period varying from 5 days to 5 months and can progress in various forms: acute, chronic or as ymptomatic (Nimri, 2003). To reduce economic losses from brucellosis, accurate, safe and sensitive diagnostic methods play avital role in the control and eradication program of brucellosis in animals and humans. The gold standard for the diagnosis of brucellosis is the isolation of the pathogen. However, isolation of the organism is time consuming and resourceintensive. Organism handling also requires specialized laboratory, bio-containment facilities and highly skilled personnel to handle clinical samples and live bacteria for eventual identification, speciation and biotyping (Kaltungo et al., 2014). Consequently, serological assays are frequently used for diagnosis of animal brucellosis particularly in cattle, sheep, goats and camels but cross- 
reactions with other pathogens including Yersinia enterocolitica, Salmonella genus, Escherichia coli O:157 and other gram negative bacteria till now represent a big problem (Nielsen et al., 2004).

In order to overcome these difficulties, polymerase chain reaction (PCR) based assays have been developed for the rapid identification and confirmation of microbes including Brucella, which almost completely obviate the need for direct handling of the pathogen. PCR has been developed for the detection of Brucella in a wide variety of clinical samples such as aborted fetuses (Buyukcangaz et al., 2011) and lymphoid tissue (Ilhan et al., 2008) and has been introduced as an accurate and sensitive assay for detection of Brucella spp. Alternative methods for the detection of Brucella organism in tissues include Immunohistochemical examination of paraffin wax- embedded tissues which is not only both sensitive and specific but also clearly shows tissue morphology; it is, therefore, capable of demonstrating the distribution of organisms in the tissues, a valuable attribute for the study of pathogenesis of B. abortus infection (Meador et al., 1986 and Perez et al., 1998).

Despite the vigorous attempt for more than one century to come up with a definitive diagnostic technique for brucellosis, diagnosis still relies on the combination of several tests to avoid false negative results (Poiester et al., 2010).

The aim of this study was planned to: (i) compare the diagnostic performance of serological standard RB and iELISA and CFT in aborted bovine, and molecular PCR studies on abomasal content of aborted fetus with known bacteriological status (ii) study the histopathological changes in the internal fetal organs and placenta of dams infected with brucella, in addition detection of the organism in infected tissues by immunohistochemical and electron microscopical techniques.

\section{MATERIALS AND METHODS}

\section{Animals and history}

The present study was carried out on a total number of 78 animals including 48 cows and 30 buffalos obtained from farms located in ElGharbia Governorate of known history of brucellosis. These animals suffered from abortion in late stage of pregnancy. None of the animals were previously immunized against Brucella.

\section{Samples collection}

A. Blood samples:
Seventy eight blood samples (48 from cows and 30 from buffalos) were collected and then serum samples were separated and preserved at $-20^{\circ} \mathrm{C}$ until used for serological assessments. Strictaseptic precautions were taken during collection of samples and different disposable gloves were used for the collection of each sample.

\section{B. Aborted fetuses:}

Aborted fetuses from serologically positive animals for brucellosis were used. Abomasal contents of aborted fetuses which were collected under sterile hygienic conditions and were immediately transported to the laboratory in a cooler with ice packs for bacteriological and molecular examination. Internal organs of the fetuses which included liver, spleen, lung and placenta were collected for Pathological, Immunohistochemistry and Ultra structural examination.

\section{Serological examination}

All sera were screened for antibodies against Brucella by Tube agglutination test (TAT), Rose Bengal plate test (RBPT), indirect ELISA (as screening tests) and Complement fixation test (CFT) (as confirmatory test) described by (Alton et al., 1988).

\section{Bacteriological examination}

Abomasal contents were cultured on $7 \%$ blood agar (Oxoid, CM 271) and Brucella Medium (Oxoid, CM 169) supplemented with Brucella Selective Supplement (Oxoid, SR209E). Cultures were incubated at $37^{\circ} \mathrm{C}$ for 5 to 7 days aerobically and microaerobically (Microaerobic kit, Merck, Anaerocult C) according to the method of (Ribierio and Herr 1990).

\section{Pathological examination:}

Complete post mortem examination was done on aborted fetuses to detect any gross pathological lesions. Small pieces from internal organs of the fetus of aborted bovine positive by using CFT (57) which included liver, spleen, lung and placenta were fixed in $10 \%$ neutral buffer formalin for $72 \mathrm{hrs}$ then we used the routine histological processing to prepare the sections according to (Bancroft et al., 1996).

\section{Immunohistochemistry}

Brucella melitensis antigens were demonstrated by using the avidin-biotin-peroxidase complex immunehistochemistry staining method. Formalinfixed, paraffin embedded tissue sections of lung, liver, spleen and placenta on coated positive slides were used and deparaffinised in xylene for $10 \mathrm{~min}$ and rehydrated through a series of graded alcohol. Heat mediated antigen retrieval was used by 
immersing the slides in citrate buffer solution and heated in microwave oven for $10 \mathrm{~min}$ at $\operatorname{low}(55-$ $60^{\circ} \mathrm{C}$ ) temperature. Blocking with $3 \%$ hydrogen peroxidase for $5 \mathrm{~min}$ at room temperature inactivated the indigenous peroxidase. The sections were washed with PBS and blocked with $5 \%$ bovine serum albumin (Gibco, USA) for $15 \mathrm{~min}$ at $37^{\circ} \mathrm{C}$, followed with overnight incubation at $4^{\circ} \mathrm{C}$ with primary poly colonal anti brucellamelitensis antibody prepared in rabbit (1:100) (Difco. lab. USA). The sections were then incubated with secondary antibody (IgG goat anti rabbit) (Abcam, UK) for $1 \mathrm{~h}$ at $37^{\circ} \mathrm{C}(1: 500)$. The slides were rinsed and washed with PBS before diaminobenzidine DAB (Dako, USA) was used as chromogen for $15 \mathrm{sec}$. Mayer'shaematoxylin stain was used as counter stain and covered with glycerin gell and examined by light microscope. The degree of IHC staining was scored as strong positive brown staining (+++ve), moderate brown staining, (++ve) and mild brown staining (+ve) (Haines, and Clark, 1991).

\section{Ultra structural Investigation:}

Small pieces of $1 \mathrm{~mm}$ from lung, liver, spleen and placenta from all examined aborted bovine positevly by using CFT (57) were collected washed, fixed with $3 \%$ glutraldehyde, and processed for transmission electron microscopy according to (Bancroft and Stevens 1982 and cheville et al., 1996) and examined using JEOL -JEM.1400 Electron Microscope at Faculty of Agriculture Research Park (FARP).

\section{Polymerase chain reaction $(\mathrm{PCR})$ DNA extraction:}

From each animal, $10 \mathrm{ml}$ of abomasal contents of aborted fetuses were collected by $21 \mathrm{G}$ sterile needle. DNA extraction and purification were performed according to the method of (Fekete et al., 1992).

Oligonucleotide primers: B. abortus, B. melitensis and IS711 primers sequence used as described (Bricker \& Halling, 1994).

Table 1: Sequences of the oligonucleotide primers used in PCR as say.

\begin{tabular}{ll}
\hline \multicolumn{1}{c}{ Primer } & \multicolumn{1}{c}{ Sequence $\left(\mathbf{5}^{\prime}-\mathbf{3}^{\prime}\right)$} \\
\hline B.abortus-specific primer & GAC-GAA-CGG-AAT-TTT-TCC-AAT-CCC \\
\hline B.melitensis-specific primer. & AAA-TCG-CGT-CCT-TGC-TGG-TCT-GA \\
\hline IS711-specific primer & TGC-CGA-TCA-CTT-AAG-GGC-CTT-CAT \\
\hline
\end{tabular}

Amplification of Brucella-DNA and detection of PCR products. PCR conditions were performed as described by (Bricker and Halling 1994).

DNA amplification in conventional PCR: DNA amplification was done in 25 ul reaction volume containing $5 \mathrm{ul}$ of Taq master ready-to-use mixes for PCR (Jena Bioscience, Cat No. 102S), 10 PM of each oligonucleotide primers, $5 \mathrm{ul}$ of DNA template and fill up to $25 \mathrm{ul}$ with molecular grade water. The optimized cycling conditions consisted of 40 cycles of $1 \mathrm{~min}$. at $95^{\circ} \mathrm{C}, 2$ minute at $60^{\circ} \mathrm{C}$ and $1 \mathrm{~min}$. at $72^{\circ} \mathrm{C}$; and final extension step at $72^{\circ} \mathrm{C}$ for 5 min. (Bricker \& Halling, 1994). The negative control contained sterile water instead of DNA template, while, the positive controls was DNA isolated from B. melitensis Rev1 were used.

Electrophoresis of PCR product: Amplification PCR products was analyzed by electrophoresis through $1.5 \%$ agarose gel stained with etidium bromide solution $(0.5 \mathrm{mg} / \mathrm{ml})$ and visualized under an ultraviolet transilluminator and photographed. Visible bands of PCR products with the molecular sizes of 498 and $731 \mathrm{bp}$ were considered indicative for identification as B. abortus and B. melitensis, respectively.

\section{RESULTS}

\section{Serological, bacteriological and molecular assessments:}

Serological examination for incidence of Brucell aspp. among aborted cows and buffaloes using RBPT, Tube agglutination test (TAT) and iELISA as screening tests and CFT as confirmatory test revealed that $60(76.92 \%), 55$ $(70.51 \%), \quad 58 \quad(74.36 \%)$ and $57 \quad(73.08 \%)$ samples were positive result respectively (Table 2). Brucellae melitensis biovar 3 was isolated from 52 (abomasal content) of aborted fetuses (31cows and 21 buffaloes). PCR assay for detection of Brucella DNA in aborted fetuses were positive in 55 examined animals (33 cows and 22 buffaloes) (Table 3).

Gross lesions: In this study the abortions occurred in the seventh and eighth months of gestation. Gross lesions were present in all naturally infected fetuses. Differences in the character or distribution of lesions in these fetuses were not noticed. Their subcutaneous tissues were oedematous and their thoracic and abdominal cavities contained an excess of thin red-tinted fluid. Most of the infected fetuses had 
changes in lungs, which observed purpletotan, firm areas were noticed throughout affected lung lobes. In several fetuses, both caudal lobes were entirely involved. The lobes were gray, firm and enlarged with indentations from adjacent ribs. Pleural roughening and tags were seen infrequently. Liver and spleen were enlarged and congested. Placenta from aborted cows and buffaloes had severe congested placenta with pale white foci (Fig 2A).

Histopathological findings: Histopathological examination revealed two types of pneumonia were observed in the lung, suppurative Bronchopneumonia (22 cows fetus and 14 buffaloes fetus) and interstitial pneumonia (13cows fetus and 8 buffaloes fetus). In fetuses with severe suppurative bronchopneumonia, moderate to large amounts of fibrin, cellular debris, macrophages and neutrophils were observed in exudates in the bronchioles and alveoli (Fig.2B). Degenerative changes were also evident in the mucosa of the bronchi or bronchioles of these fetuses. Smaller airways have macrophages and cell debris. Vascular hyperemia and perivascular accumulations of macrophages and neutrophils were the other microscopic findings. In some fetuses, there was amniotic debris. While the lungs with interstitial pneumonia were characterized by severe lymphocytic infiltration into the interalveolar septa with edema these changes tended to have a multifocal distribution. (Fig. 2C).

Livers of aborted fetuses showed diffuse reticuloendothelial cell hypertrophy. All of the affected fetuses had randomly scattered mild to moderate, periportal, mononuclearcell and/ or neutrophils infiltration (Fig.2D). intrasinusoidal granulomatous nodules Mild to severe hydropic degeneration in the hepatic parenchyma were also showed.

The pathological finding in the spleen of infected fetuses were slight lymphoid depletion of the white pulp and mild neutrophils infiltration (Fig.2E). These changes accompanied by diffuse and multifocal reticuloendothelial hyperplasia and mild lymphoid hyperplasia circumscribing splenic vessels. In some cases intra-and subcapsular mononuclear leukocyte infiltration. Small irregular area of necrosis in the splenic red pulp were seen spleen.
Histopathological examination of the placenta of aborted bovine showed necrotic placentitis, characterized by superficial to deep necrosis of the carunculae, associated with haemorrhage, neutrophilic exudates, intralesional and retained fetal tissues in the caruncularcrypts (Fig.2F) in addition large multiple area of dystrophic calcification.

Immunohistochemical findings: Regarding to the immunohistochemical examination, the positive Immunoperoxidase staining of Brucellamelitensis antigens were showed as brown, finely granular intracytoplasmic staining 54 positive samples and out of 57 from positive animals using CFT.

In our study, strong positive reaction $(+++v e)$ were located in the cytoplasm of macrophages in the cellular debris of alveoli and bronchi of the fetal lung, and in placenta both extracellular in necrotic areas and intracellular within macrophages, neutrophils and trophoblastic cells. Moderate positive reaction (++ve) showed in isolated macrophages in the sinusoids and interstitium in the cytoplasm of macrophages in the red splenic pulp and sinusoids of fetal spleen. While mild positive reaction (+ve) intracellularly the cytoplasm of macrophages and Kupffer cells of the fetal liver, Similarly, the antigens were present within cytoplasm of some hepatocyte (Fig. 3A-3D), biliary duct epithelial cells as well as isolated macrophages in the sinusoids and interstitium. Also, the immunreactivity were found in the cytoplasm of macrophages in the red splenic pulp and sinusoids of fetal spleen. Brucellamelitensis antigens were observed in placenta in both extracellular in necrotic areas and intracellular within macrophages, neutrophils and trophoblastic cells.

Ultra-structural findings: TEM of lung showed the cytoplasm of neutrophil and macrophages containing electron dens bodies of cocobacilli were present in the interstitium and located near the proliferating type II alveolar cells (Fig.4A).TEM of Spleen showed neutrophils and macrophages containing moderate aggregations (clusters) of electron dens bodies of intact cocobacilli within the cytoplasm, with partial lysis of its cytoplasm (Fig 4B).TEM of placenta revealed that the Trophoblasts filled with organisms (Fig.4C )were often degenerate; they were swollen and had electron-lucent cytoplasm, lipid droplets, and dilated membranous cisternae devoid of ribosomes, In necrotic infected trophoblastic cells, cisternae were fragmented, and brucellae were free in the cytosol. 
Table 2: Results of serological tests for the recognition of brucellosis in aborted cows and buffaloes.

\begin{tabular}{lcccccccc}
\hline Examined animals & \multicolumn{7}{c}{ Serological tests } \\
\cline { 2 - 9 } & \multicolumn{1}{c}{ RBT } & \multicolumn{2}{c}{ TAT } & \multicolumn{2}{c}{ iELISA } & CFT \\
\cline { 2 - 9 } & NO & $\%$ & NO & $\%$ & NO & $\%$ & NO & $\%$ \\
\hline cows $(\mathrm{N}=48)$ & 37 & 77.08 & 32 & 66.67 & 35 & 72.92 & 35 & 72.92 \\
\hline buffaloes $(\mathrm{N}=30)$ & 23 & 76.67 & 23 & 76.67 & 23 & 76.67 & 22 & 73.33 \\
\hline Total $(\mathrm{N}=78)$ & 60 & 76.92 & 55 & 70.51 & 58 & 74.36 & 57 & 73.08 \\
\hline
\end{tabular}

Table 3: Bacteriological culture, PCR assay and IHC in aborted fetuses from serologically positive dams

\begin{tabular}{lcccccccc}
\hline & $\begin{array}{c}\text { Serological } \\
\text { Positive* }\end{array}$ & $\begin{array}{c}\text { Bacteriological } \\
\text { culture** }\end{array}$ & PCR** & \multicolumn{5}{c}{ IHC*** } \\
\cline { 5 - 8 } cows $(\mathrm{N}=48)$ & 35 & 31 & 33 & 5 & 6 & 11 & 11 \\
\hline buffaloes $(\mathrm{N}=30)$ & 22 & 21 & 22 & 2 & 4 & 7 & 8 \\
\hline Total $(\mathrm{N}=78)$ & 57 & 52 & 55 & 7 & 10 & 18 & 19 \\
\hline
\end{tabular}

$*=$ CFT positive

$* *=$ Abmoasal content

$* * *=$ lung. liver. spleen and placenta

$* * *=$ lung, liver, spleen and placenta

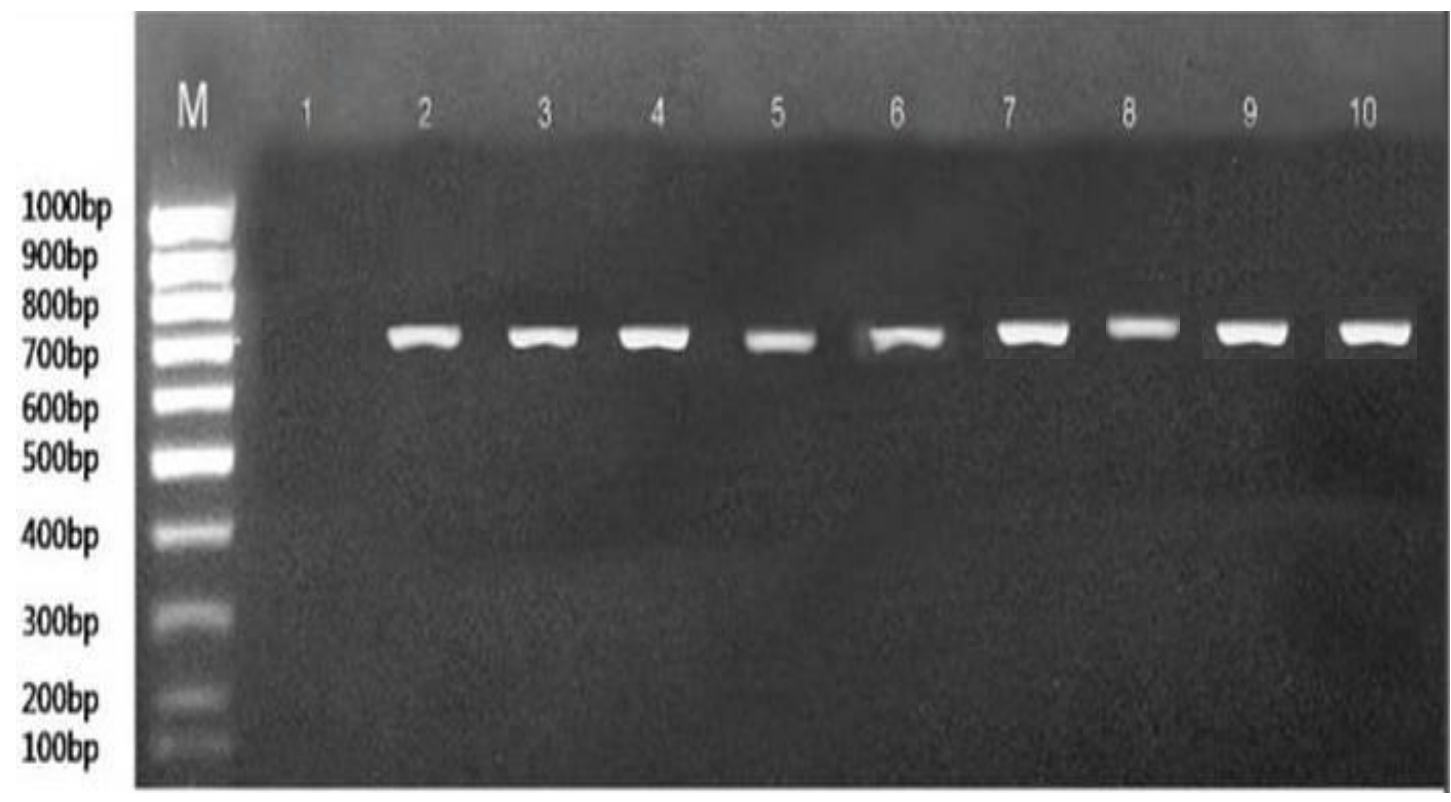

Figure 1: PCR assay for detection of Brucella Spp. Lane 1: DNA marker; lane 2: control negative, lane 3: control positive lanes 4-7: positive

Figure 1: lane 1 control negative, lane 2 control positive, lane 3-10 positive samples 731 

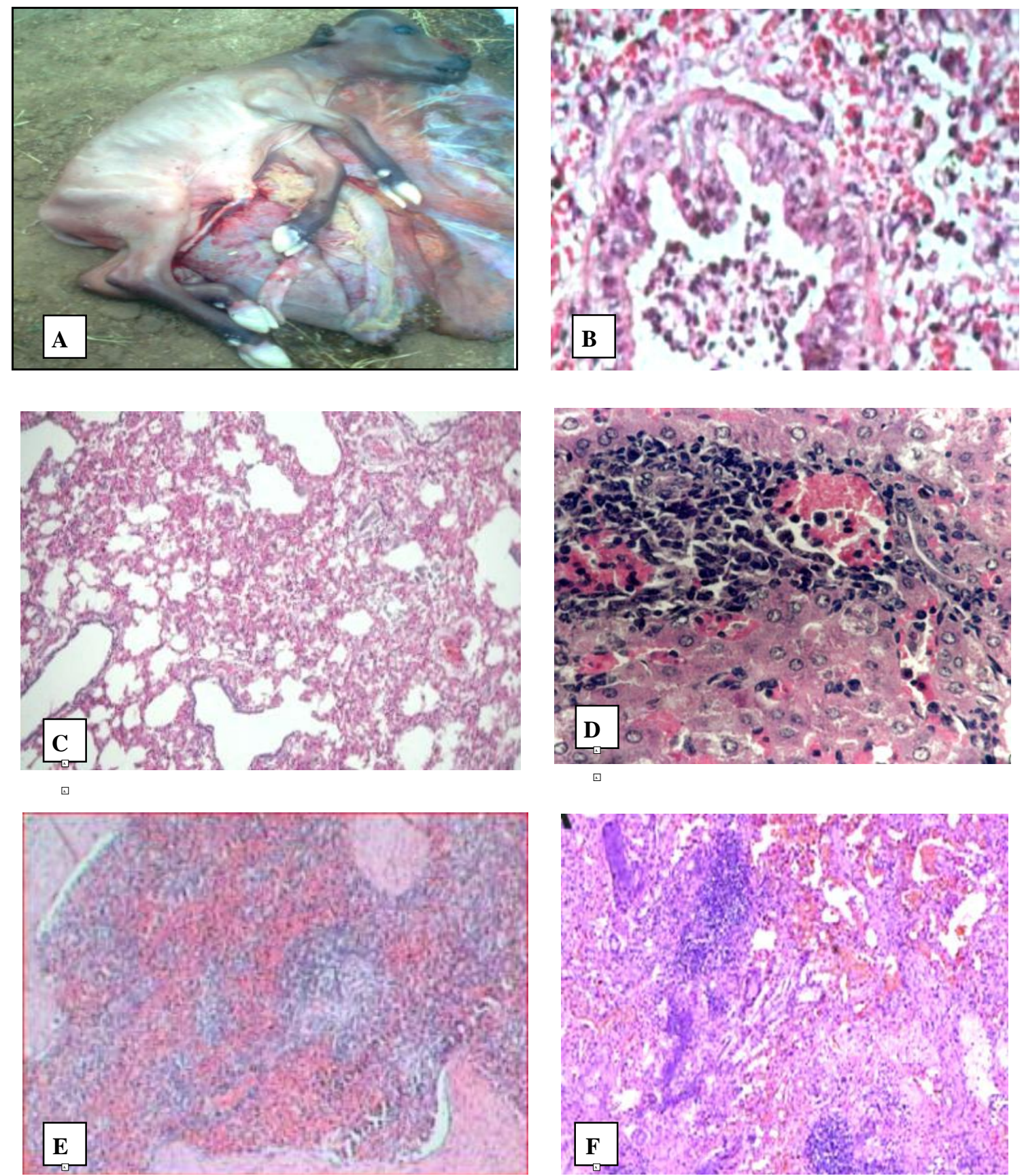

⿷

Fig. 2: (A), Aborted fetus due to brucellosis, with edema, opaque and bleeding of placenta fetal. (B), lung bronchiole showing inflammatory cell Infiltrate in the lumen and adjacent parenchyma H\&E; X200. (C), fetal lung showing Interstitial pneumonia with area of alveolar emphysema, the alveolar septa are infiltrated with mononuclear cells (H\&E) x100. (D), fetal liver showing perivascular polymorphic cell infiltration ( H\&E; X400.) (E), spleen of calf showing lymphoid depletion, mild neutrophil infiltration and hemosiderin granules scattered in splenic parenchyma (H\&E;X100). (F), Cow; placenta showing caruncular crypts filled with necrotic debris, multifocal hemorrhage, intense inflammatory infiltrate, (H\&E;X100). 

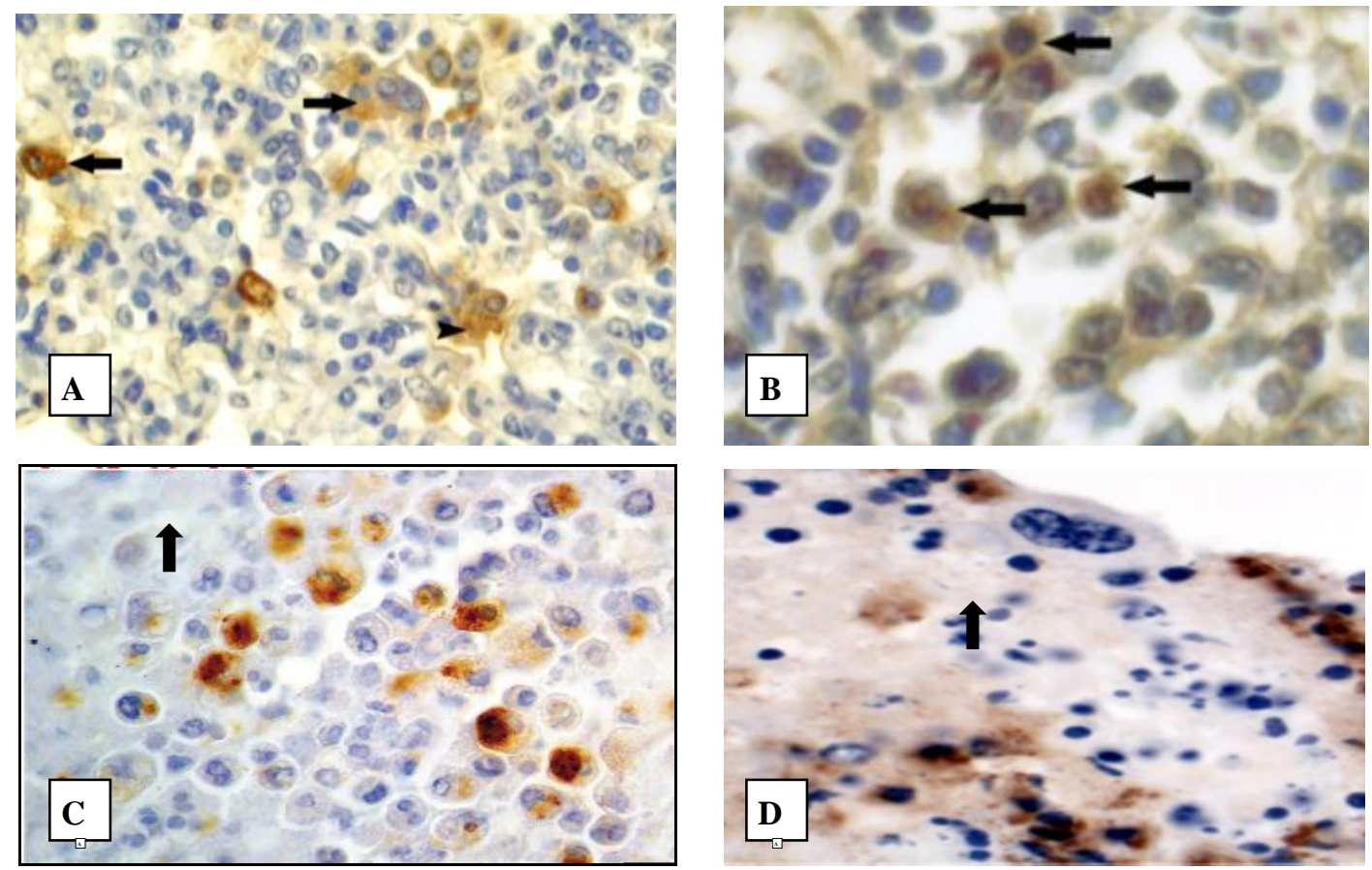

Fig. 3: (A), Photomicrograph of fetal lung showed Immunoreactivity to the anti-Brucellamelitensis polyclonal antibody in several macrophages and cellular debris (arrowhead) X 200. (B), Photomicrograph of fetal liver showed Immunoreactivity to the anti- Brucellamellitensis polyclonal antibody in the cytoplasm of macrophages and Kupffer cells $x$ 400. (C), Photomicrograph of fetal spleen Immunoreactivity to the anti- Brucellamellitensis polyclonal antibody in the cytoplasm of macrophage of the Red pulp x 400. (D), Photomicrograph of placenta showed Chorionic membrane with trophoblastic cells containing intracellular immune Brucellamelitensis. x 400.

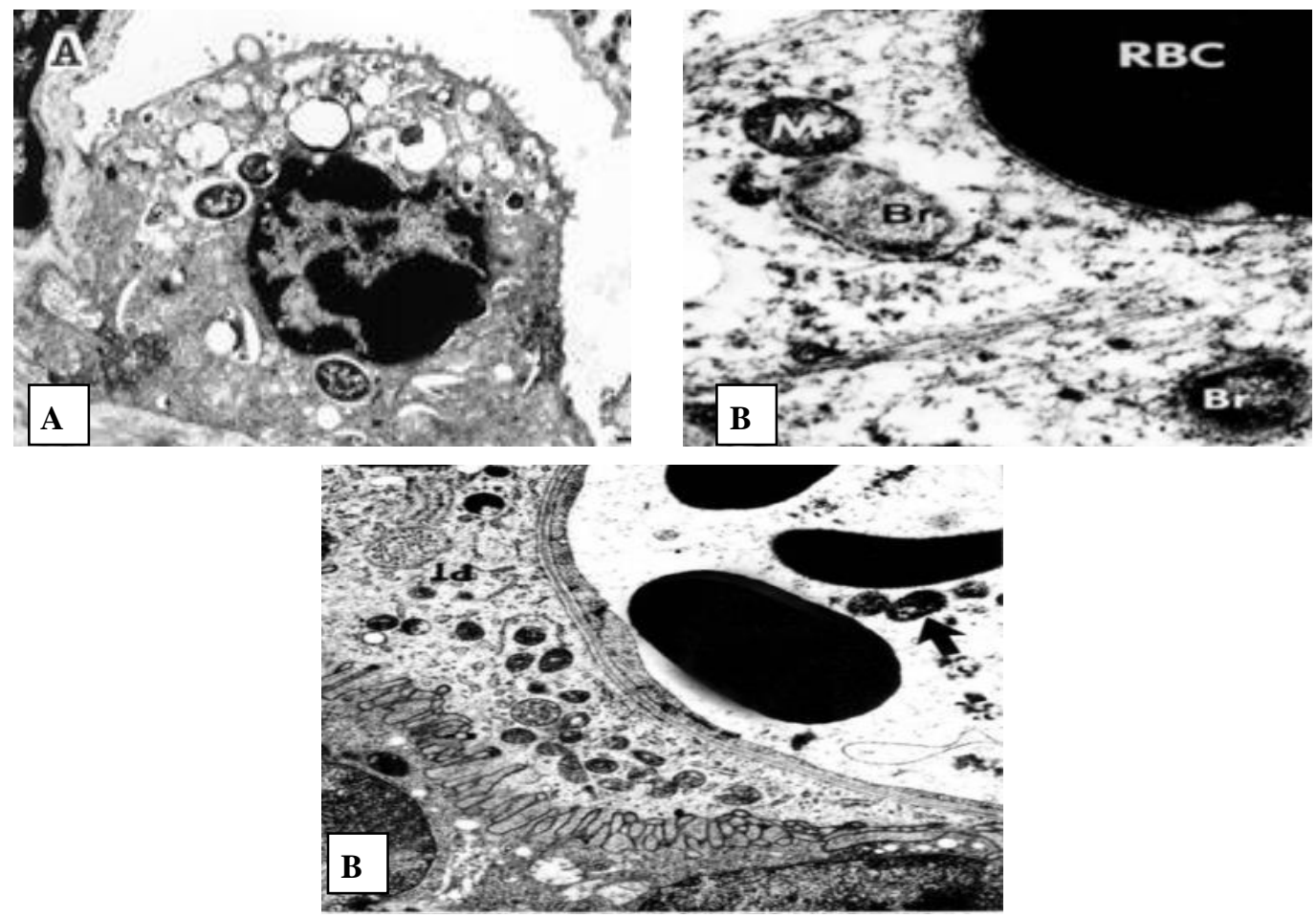

Fig. 4: (A), T.E. Micrograph of fetal lung showed brucella (arrow) in type alveolarepithelial cells X10000 (B), T.E. Micrograph of fetal spleen revealed the presence of moderate aggregates of brucella coco bacilli $(\mathrm{Br})$ in macrophage swelling of mitochondria (M). adjacent erythrocyte (RBC) X10000. (C), T.E. Micrograph of placenta showed B. melitensis Filled trophoblasts (arrow), and free brucellae, Sub epithelial capillaries contained intraluminal cocobacilli adjacent erythrocytes (arrow) $\mathrm{X} 10000$ 


\section{DISCUSSION}

Brucellosis is a worldwide zoonotic disease that is recognised as a major cause of heavy economic losses to the livestock industry and poses serious human healthhazard (Ocholi et al., 2005). Abortion is a frequent complication of brucellosis in animals, where placental localization is believed to be associated with erythritol, a growth stimulant for $B$. abortus. Results of clinical sings of aborted cows and buffalos were similar to the results of many researches who explained that abortion in cattle due to brucellosis occurred at late stage of pregnancy and may result in the birth of nonviable calves and retained placentas (Gabli et al., 2015).

The presumptive diagnosis provided by the serological tests, is usually accepted as indication of brucellosis. Rose Bengal Plate Test (RBPT), Complement Fixation Test (CFT), and Tube agglutination test (TAT) are utilized in this study for the detection of antibodies specific to Brucella spp (Pandeya et al., 2013). Serological examination performed by RB test in the present study gave higher number of positive samples $60(76.92 \%)$, as RBT assay can detect antibodies of classes IgG1 and IgM against surface antigen lipopolysaccharides (LPS) of smooth Brucella (Davies, 1971). Indeed, this test is internationally acknowledged as the choice for the screening of brucellosis in ruminants (Garin-Bastuji and Blasco, 2004). TAT assay isapproved by the veterinary authority organization in Egypt. However, chronic carriers produce mainly IgG1that block the agglutinating activities of IgG2 (Farina, 1985) which may result in lower detection rates. This mayexplain the lower number of positive samples detected by TAT $55(70.51 \%)$ in comparison to other serological tests used. Excess of antibodies resulting in false negative reaction due to prozone effect (Afify et al., 2013). RBPT provided positive reactors more than TAT, more over due to its ability for earlier detection of recently infected animals as well as the longer persistence of its reaction in those chronically infected as mentioned by (Awad et al., 1977).

In the present study, iELISA provided positive reactors less than RBPT. Similar findings given by (Saravi et al., 1995), (Hermoon et al., 2001) who reported that ELISA has been shown to be suitable test for large scale screening for Bovine Brucellosis. Besides latent infection could be detected earlier by ELISA than other serologicaltests as it detect all classes of antibodies.

CFT is considered as gold standard serological test used for detection of brucellosis as it detect only IgG specific for brucella infection so it overcome crossreaction with other similar gram negative bacteria and so no false results detected
Additionally, World Organisation for Animal Health (OIE) suggested that CFT is a test approved all over the world (OIE 2009). This test is considered as a high-quality test when correctly used, however it has lots of practical drawbacks such as time consuming and difficult to standardize (Abernethy et al., 2012). Confirmatory diagnosis must be provided by the isolation of etiological agents. Therefore, the isolation of $\mathrm{Br}$. Melitensis is important to study the epidemiology of brucellosis.

Brucellae melitensis biovar 3 was isolated from 52 aborted bovine ( 31 cows and 21 buffaloes) out of 57 serologically positive by CFT $(91.22 \%)$. The studies in various parts of Egypt indicate that the $B r$. Melitensis biovar 3 is the most prevalent field strain (Montasser, 1991 and Afify et al., 2013). The isolation of $\mathrm{Br}$. Melitensis strains indicated very high prevalence of $\mathrm{Br}$. Melitensis infection among these animals in this region and due to that, the disease may threat human and animal health which was coincide (Esmaeil et al., 2008).

PCR amplification using published set of primers also resulted in specific amplicon of expectedsize $(731 \mathrm{bp})$ in 33 abomasal content of aborted fetus cow and in 22 abomasal content of aborted fetus buffaloes while no band was observed in negative control (Fig.1). Amplification of microbial DNA from clinical samples offers the potential for rapid, sensitive and specificidentification of pathogens, either directly from tissues or body fluids or after culture of such samples (Gupta et al., 2006). The high incidence of $B$. melitensis in abomasal content samples of unspecific hosts of this present study may show that these animals had been maintained in closeassociation with infected sheep (Kaltungo et al., 2013).

Molecular biology techniques are advancing as a diagnostic tool and will soon be at the point of replacing actualbacterial isolation. These techniques are rapid, safe and cost effective, the only real problems being some uncertainties regarding their specificity. PCR is considered as alternative methods for the failure of culturing and identification of Brucella spp. by traditional methods (Samadi et al., 2010). Therefore, PCR technique has been revealed to be an important technique for identifying DNA of bacteria and affords a promising alternative method for diagnosis of animal brucellosis.

In this study, Brucella meletensis positive aborted bovine fetuses developed histopathologic changes similar to those in experimental and natural infections in cattle (Palmer et al., 1996; Perez et al., 1998) and buffaloes (Rhyan et al., 2001). A series of pathologic 
changes in bovine fetuses infected with $\mathrm{Br}$. melitensis occur including pneumonia, (López et al., 1984; Hong et al., 1991). Bovine fetal pneumonia is the most common lesion and is considered to be diagnostic of Brucellae infection by many authors (Meador et al., 1989 and Perez et al., 1998). In the present study, characteristic pulmonary lesions were bronchopneumonia or interstitial pneumonia which are the most common lesions of aborted fetuses infected with Br. melitensis. (Perez et al., 1998; Khoudair et al., 2009). In this study, in some cases bronchi and bronchioles lumens contained aspirated amniotic fluid and generally considered an important Brucellae infection route in affected fetuses (López et $a l .$, 1984). Hepatitis is a recognized sequel of chronic brucellosis in humans (Aygen 1998) and other animals (Elzer et al., 1998 and Song et al., 2008). In the present work, lesions in the liver and spleen typically were diffuse reticuloendothelial hypertrophy, periportal and sinusoidal infiltration of a mixture of lymphocytes with smaller numbers of macrophages. Histological changes described in this report are similar to those recognized in cattle (Perez et al., 1998 and Barquero-Calvo et al., 2007). As in the present study, mild-to-moderate lymphoid hyperplasia circumscribing splenic arteries and splenic focal necrosis have been described in bovine fetuses (Hong et al., 1991 and Khoudair et al., 2009), yet was not observed in caprine and ovine (Yazicioglu 1997). It would seem possible that the increased splenic inflammation was in fact manifestation of an effective immune response. It was recently demonstrated in mice that virulent Brucella induced a strong pro-inflammatory response in the spleen, as assessed by evaluating the gene expression profile (Roux et al., 2007).

Necrotic neutrophilic placentitis with perivascular infiltrate, which was the most frequently observed microscopical change in experimentally infected bovine, was associated with large numbers of B.melitensis intracellularly in macrophages and trophoblasts and also extra cellularly in necrotic tissues. Trophoblasts are thought to be the primary target cell for invasion and multiplication of $\mathrm{Br}$. melitensis in the placenta (Anderson et al., 1986 and Dey et al., 2013). This tropism may be due to the presence of erythritol, or to hormone synthesis by trophoblastic cells (Samartino and Enright, 1993). The specific immunoreactivity which was seen as intense granular staining reaction against the $\mathrm{Br}$. Melitensis antigen was detected mainly in the macrophage cytoplasm, in some neutrophils and cellular debris. Regarding to the immunohistochemical examination, the positive Immunoperoxidase staining fo Brucellamelitensis antigens were showed as brown, finely granular intracytoplasmic staining 54(33 cows and 21 buffaloes) positive samples out of 57 from positive animals using CFT. The higher number of positive
IHC werein spleen and placenta. In the present study two fetuses were positive by immunohistochemistry and negative by bacteriologic culture. The reasons possibly due to degenerated microorganisms, deficient isolation technique, or cross reaction of antibody with another antigen (Perez et al., 1998).

An intense antigenic reaction was mainly localized in the cells of the inflammatory foci of the lung, liver, spleen and placenta. However, some isolated inflammatory cells reacted weakly or negative. Similarly, previous reports shown that organisms were located mainly in the cytoplasm of the macrophages in the inflammatory foci (Perez et al., 1998).

In our study, Ultrastructure examination of placenta indicates that Brucellamelitensis first enters and replicates within erythrophagocytic trophoblasts. We believe that $\mathrm{Br}$. melitensis next replicates in the rough endoplasmic reticulum of chorioallantoic trophoblasts (Fink and Cookson 2005). Chorionic villi and fetal viscera are infected hematogenously after trophoblast necrosis and ulceration of chorioallantoic membranes have occurred. It is likely that $\mathrm{Br}$. Melitensis present in placentomal chorionic villi caused vasculitis and separation of trophoblasts from maternal syncytial epithelium. The numerous $\mathrm{Br}$. Melitensis present in chorionic connective tissue may be due to failure of fetal phagocytes to destroy Brucella and subsequent bacterial replication. Degenerative fetal phagocytes containing intact brucellae were prevalent in chorionic villi (Pei, and Ficht, 2004).

\section{CONCLUSION}

Definitive diagnosis of brucellosis remains a difficult task. The only diagnosis, which is the 'gold standard', is the isolation of the causative agent from the host. However, it is associated with some problems: low sensitivity, cost and danger due to laboratory infection of personnel. Indirect testing of antiBrucella spp. antibodies in serum, and other clinical specimens are routinely used in brucellosis control and eradication programmes. These tests have, however, been shown to be inconclusive, leading to culling of Brucella-free animals and subsequent economic loss. Molecular biology with selected primers as a diagnostic tool is advancing with promising results, and may soon be at the point of replacing actual bacterial isolation. It is rapid, safe and cost-effective, the only real problems, being some uncertainties regarding specificity. The use of immunohistochemistry and electronmicroscopical technique is particularly useful tools for diagnosis of bovine abortion caused by Brucellamelitensis specially in suspected cases with negative bacteriologic culture and in cases when serology is not possible. 


\section{REFERENCES}

Abernethy, D.A.; Menzies, F.D.; McCullough, S.J.; McDowell, S.W.; Burns, K.E.; Watt, R.; Gordon, A.W.; Greiner, $M$. and Pfeiffer, D.U. (2012): Field trial of six serological tests for bovine brucellosis. Vet. J.; 191(3): 364-370.

Afify, M.; Al-Zahrani, SH. and El-Koumi, MA. (2013): Brucellosis-induced Pancytopenia in Children: A Prospective Study. Life Sci. J.10:1.1364-8

Alton, G.G.; Jones, L.M.; Angus, R.D. and Verger, J.M. (1988): Techniques for the brucellosis laboratory, 17-62. Institutional de la Recherché Agronomique, Paris.

Anderson, TD.; Meador, VP. and Cheville, NF. (1986): Pathogenesis of placentitis in the goat inoculated with Brucellaabortus. I. Gross and histologic lesions. Vet Pathol 23: 219-226.

Ashford, D.A.; Lingappa, J.; Woods, C.; Noll, H.; Neville, B. and Perrkins, B.A. (2004): Adverse events in human associated with accidental exposure to the livestock brucellosis vaccine RB51. Vaccine. 22: 3435-3439.

Awad, F.; Amin, M.M.; Shawkat, M.E.; Fayed, A.A. and Matter, A.A. (1977): Comparative studies on milk ring and agglutination tests in the diagnosis of brucellosis in cattle and buffaloes in Egypt. Egypt. J. Vet. Sci., 14(2): 135140.

Aygen, B (1998): Prostatitis and hepatitis due to Brucellamelitensis: a case report. J Infect 36: 111-112

Bancroft, J.D. and Stevens, A. (1982): Electron microscopy2: transmission (A) tissue preparation, (B) section and staining In: Theory and practice ofhistological technique, 2nd Ed., G. Robinson, Churchill Livingstone inc., New York, pp: 482-518.

Bancroft, J.D.; Stevens, A. and Turner, D.R. (1996): Theory and practice of histological technique, 4th Ed., Churchill Livingstone Co., New York, USA.

Barquero-Calvo, E.; Chaves-Olarte, E.; Weiss, DS.; Guzma' n-Verri, C., Chaco'n-Dı'az C et al. (2007): Brucellaabortususes a stealthy strategy to avoid activation of the innateimmune system during the onset of infection. 2, e631. 10.1371/journal.

Bricker, B.J. and Halling, S.M. (1994): Differentiation of Brucellaabortusbv. 1, 2 and 4, Brucellamelitensis, Brucellaovis and Brucellasuisbv. 1 by PCR. J. Clin. Microbiol., 32: 2660-2666.

Buyukcangaz, E.; Sen, A.; Carli, K.T. and Kahya, S. (2011): Comparison of direct culture versus
PCR for the detection of Brucella in aborted fetuses of cattle and sheep in Turkey. Vet Rec. 168: 430-439.

Cheville, N.F.; Olsen, S.C.; Jensen, A.E.; Stevens, M.G.; Florance, A.M.; Houng, H.S.H.; Drazek, E.S.; Warren, R.L.; Hadfield, T.L. and Hoover, D.L. (1996): Bacterial persistence and immunity in goats vaccinated with a pur Edeletion mutant or the parental $16 \mathrm{M}$ strain of Brucellamelitensis. Infect. Immun., 64: 24312439

Davis, G. (1971): The Rose Bengal Test. Vet. rec. 88.447-449.

Dey, S.K.; Rahman, M.S.; Rima, U.K.; Hossain, M.Z.; Chowdhury, G.A.; Pervin, M.; Habib, M.A. and H. Khan, M.A. (2013): Serological and pathological investigation of Brucellosis in dairy Cows of mymens In ghdistrict, BANGLADESH Bangl. J. Vet. Med. 11 (2):107-11

Esmaeil, Z.; Abdollah, E. and Mehran, Y. (2008): Isolation and identification of Brucella organisms in Iran. Iranian.J. of Clinic Infectious Diseases. 3(4): 185-188

Elzer, PH.; Edmonds, MD. and Hagius, SD. (1998): Safety of Brucellaabortus strain RB51 in bison. J. Wildlife Dis 34: 825-829

Farina, R. (1985): Current serological methods in B.melitensis diagnosis in: Brucellamelitensis, ed. Verger JM, Plommet, M pp. 139-146Martinus Nijhoff, Dordhoff, the Netherland.

Fekete, A.; Bantle, J.A. and Halling, S.M. (1992): Detection of Brucella by polymerase chain reaction in bovine fetal and maternal tissues. J. Vet. Diagn Invest. 4: 79-83

Fink, S.L. and Cookson, B.T. (2005): Apoptosis, pyroptosis and necrosis: mechanistic description of dead and dying eukaryotic cells. Infect. Immun., 73: 1907-1916.

Gabli, A.; Agabou, A. and Gabli, Z. (2015): Brucellosis in nomadic pastoralists and their goats in two provinces of the eastern Algerian high plateaus. Tropical Animal Health \& Production.; 47: 1043.

Garin-Bastuji, B. and Blasco, JM. (2004): Caprine and ovine brucella(excluding $B$. ovis). In: Manual of Diagnostic Tests and Vaccines for Terrestrial Animals, fifth ed. OIE, pp. 598-606.

Gupta, VK.; Verma, D.K.; Singh, K.; Kumari, R.; Singh, SV. And Vihan, VS. (2006): Singlestep PCR for detection of Brucellamelitensis from tissue and blood of goats. Small Rum. Res., 66: 169-174.

Haines, D.M. and. Clark, E.G. (1991): Enzymeimmunohistochemical staining of formalin-fixed tissues for diagnosis in 
veterinary pathology. Can. Vet. J., 32: 295302.

Hermoon, CD.; Jung, B.; Cho, S.; Jung, S. and Kim, O. (2001): Development of ELISA for Brucellaabortus RB51. Purification of $8 \mathrm{KDa}$ antigen and development of ELISA using its antigen of Brucellaabortus. Korean J. Vet. Res., 41: 51-57.

Hong, CB.; Donahue, JM.; Giles, RC.; Poonacha, KB.; Tuttle, PA. and Cheville, NF. (1991): $\quad$ Brucellaabortus-associated meningitis in aborted bovine fetuses. Vet. Pathol 28: 492-496.

Ilhan, Z.; Aksakal, A.; Ekin, I.H.; Gülhan, T.; Solmaz, H. and Erdenlig, S. (2008): Comparison of culture and PCR for the detection of Brucellamelitensis in blood and lymphoid tissues of serologically positive and negative slaughtered sheep. Lett Appl Microbiol. 46: 301-306.

Kaltungo, B.Y.; Saidu, A.K.B. Sackey and Kazeem, H.M. (2014): A review on diagnostic techniques for brucellosis. African Journal of Biotechnology, Vol. 13(1), pp. 1-10,

Kaltungo, B.Y.; Saidu, S.N.A.; Sackey, A.K.B. and Kazeem, H.M. (2013): Serological evidence of brucellosis in goats in Kaduna North Senatorial district of Kaduna state, Nigeria...ISRN Veterinary Science. Article ID 963673, p: 1-6.

Kardjadj, M.; Kouidri, B.; Metref, D.; Luka, PD. and Ben-Mahdi, MH. (2016): Abortion and various associated risk factors in small ruminants in Algeria.pre Vet. Med.; 123: 97-101.

Khoudair, R.M.; Ibrahim, E.M.; Saker, G.G. and Hafez, M.A. (2009): Clinicodiagnostic and pathological studies on cattle and buffaloes sufferingfrom brucellosis and tuberculosis in Kafr El Sheikh Governorate. J. Comp. Path. \& Clinic. Path. Vol. 22 No. 1 (January) 2009; 148174.

López, A.; Hitos, F.; Perez, A. and NavarroFierro, RR. (1984): Lung lesions in bovine fetuses aborted by Brucellaabortus. Can J Comp Med 48: 275-277.

Meador, V.P.; Tabatabaia, L.B.; Hagermoser, W.A. and Deyoe, B. (1986): Identification of Brucellaabortus in formalin fixed, paraffin embedded tissues of does, goats and mice with Avidin-Biotin-peroxidase complex immuno enzymatic staining technique. Am. J. Vet. Res., 47: 21472150.

Meador, VP.; Deyoe, BL. and Cheville, NF. (1989): Pathogenesis of Brucellaabortus infection of the mammary glands in goats. Am. J. Vet. Res. 52: 886-890
Megid, J.; Mathias, L.A. and Robles, C.A. (2010): Clinical manifestations of brucellosis in domestic animals and humans. The Open Vet. Sci. J. 4: 119-126.

Montasser, A.M. (1991): Morphological and clinicopathological studies on brucellosis in large ruminants. M.V.SC. Thesis pathology. Fac. of Vet. Med. Cairo University

Nicoletti, P. and Tanya, V. (1993): Comparison of enzyme labeled Immuno- sorbant assay and particle concentration fluorescence immunoassay with standard serologic method and bacteriologic culture for detection of Brucella species infectedcows in herds with brucellosis. J. Am. Vet. Med. Ass., 202(12): 1975-1977.

Nielsen, K.; Smith, P.; Widdison, J.; Gall, D.; Kelly, L.; Kelly, $W$. and Nicoletti, $P$. (2004): Serological relationship between cattle exposed to Brucellaabortus, Yersinia enterocolitica O:9 and Escherichia coli O157:H7. Vet. Microbiol. 100: 25-30.

Nimri, LF. (2003): Diagnosis of recent and relapsed cases of human brucellosis by PCR assay. BMC Infect. Dis. 3: 5 .

Ocholi, R.A.; Kwaga, J.K.P.; Ajogi, I. and Bale, J.O.O. (2005): Abortion due to Brucellaabortus in sheep in Nigeria. Rev. Sci. Tech. Off. Int. Epiz., 24: 973-979

OIE, (2009): "Terrestrial manual, Bovine brucellosis," in Manual of Diagnostic Tests and Vaccines for Terrestrial Animals, vol. 2, chapter 2.4.3, pp. 624659, OIE, Paris, France.

Palmer, MV.; Cheville, NF. and Jensen, $A E$. (1996): Experimental infection of pregnant cattle with the vaccine candidate Brucellaabortus strain RB51: pathologic, bacteriologic and serologic findings. Vet. Pathol 33: 682-691

Pandeya, Y.R.; Joshi, D.D.; Dhakal, S.; Ghimire, Mahato, B.R. and Satyal, R.C. (2013): Seroprevalence of brucellosis in different animal species of Kailali district, Nepal. Int. J. infect. Microbiol. 2 (1): 22 - 55.

Perez, J.; Quezada, M.; Lo'pez, J.; Casquet, O.; Sierra, M.A. and Martin De Las Mulas, J. (1998): Immunohistochemical detection of Brucellaabortus antigens in tissues from aborted bovine fetuses usinga commercially available polyclonal antibody. J. Vet. Diagn. Invest., 10: 17-21.

Pei, J. and Ficht, T.A. (2004): Brucellaabortus rough. mutants are cytopathic for macrophages in culture. Infect. Immun., 72: 440-450. 
Poiester, FP.; Nielsen, K.; Samartino, LE. and $Y u$, WL. (2010): Diagnosis of Brucellosis. Open Vet. Sci. J. 4:46.

Rhyan, J.C.; Gidlewski, T.; Roffe, T.J.; Aune, K.; Philo, L.M. and Ewalt, D.R. (2001): Pathology of brucellosis in bison from Yellowstone National Park. Journal of Wildlife Diseases, 37: 101-109.

Ribierio, L. and Herr, S. (1990): The use of filter paper discs impregnated with thionin acetate, basic fuchsin and thionin blue in the identification of Brucella species. Onderstepoort J. Vet. Res. 57: 197-199.

Roux, C.M.; Rola' n, H.G.; Santos, R.L.; Beremand, P.D.; Thomas, T.L.; Adams, L.G. and Tsolis, R.M. (2007): Brucella requires a functional Type IV secretion system to elicit innate immune responses in mice. Cellular Micro-biology9, 18511869.

Samadi, A.M.; Ababneh, MK.; Giadinis, N.D. and Lafi, S.Q. (2010): Ovine and Caprine Brucellosis (Brucellamelitensis) in Aborted Animals in Jordanian Sheep and Goat Flocks Veterinary Medicine
International, Article ID 458695 , doi:10.4061/2010/458695.p 1-7.

Samartino, L.E. and Enright, F.M. (1993): Pathogenesis of abortion of bovine brucellosis. Comparative Immunology, Microbiology and Infectious Diseases, 16, 95-101.

Saravi, M.; Right, P.; Gregoret, R. and Gell, M. (1995): Comparative performance of the enzyme linked immunosorbent assay (ELISA) and conventional assays in the diagnosis of bovine brucellosis in Argentine. Vet. Immunol. Immunopathol., 47: 93-99.

Song, H. (2008): Brucella endocarditis in a nonendemiccountry: first reported case in East Asia. Circulation Journal, 72, 500e501.

WHO/OIE/FAO/CDS. (2006): Brucellosis in humans and animals 7:1-66.

Yazicioglu, O. (1997): Pathological and immunoperoxidase studies of the fetal lesions of ovine brucellosis. (Koyunlarda bruselloza baÆlı abortuslarda fötal lezyonlar üzerinde patolojik ve immunoperoksidaz çalısmalar.) Ankara Üniv. Vet. Fak. Derg 44: 291-307.

\section{دراسات مقارنة للكشف عن ميكروب البروسيلا فى اجنة الماشية المجهضة باستخدام الطرق التقليدية والمناعة الباثولوجية الكيميائية والطرق الجزية الجيئية بائية}

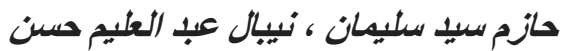

Email: hazemsoliman144@gmail.com Assiut University web-site: www.aun.edu.eg

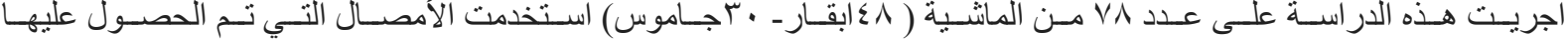

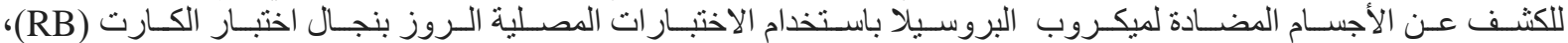

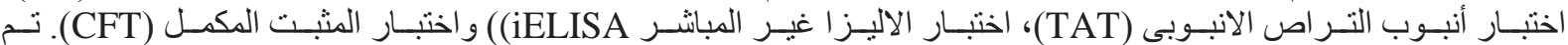

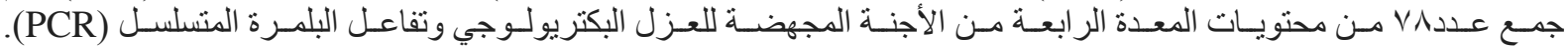

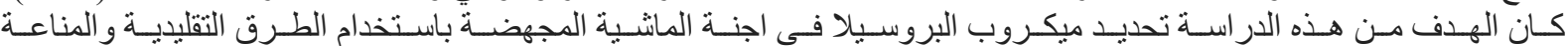

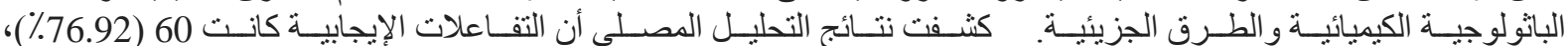

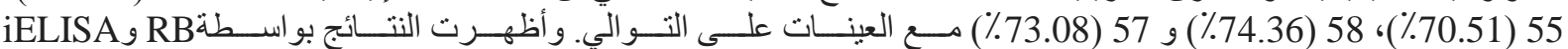

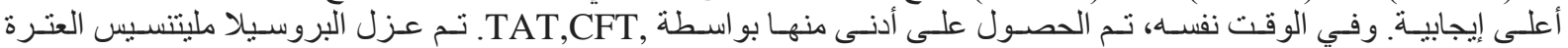

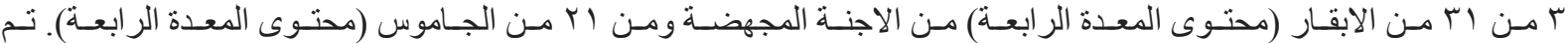

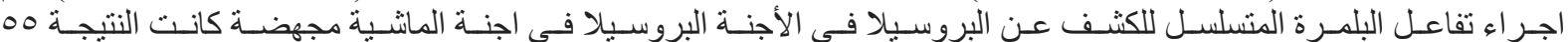

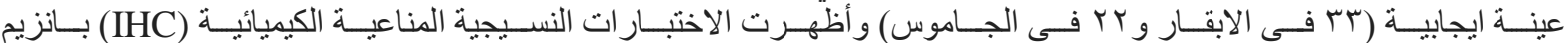

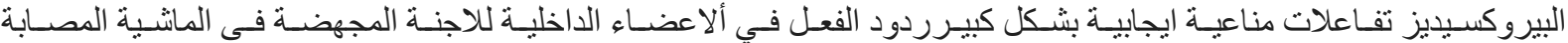

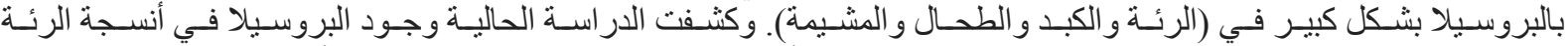

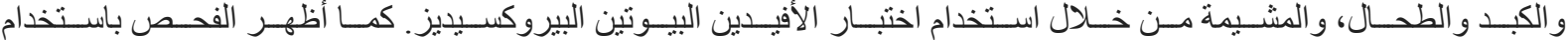

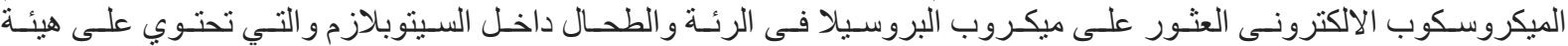
cocobacilli.

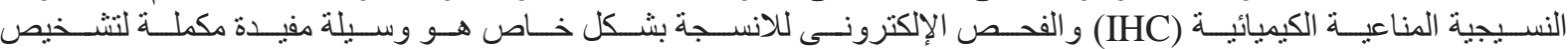

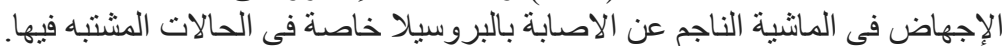

